\title{
Factors influencing Community Healthcare Worker's adoption of mobile health technology (mhealth): A case of sangini supportive supervision (sangini) app, Uttar Pradesh, India
}

\section{Sabhya Juneja ${ }^{1}$, Archna Kumar ${ }^{2}$}

${ }^{1}$ Doctoral Candidate, Department of Development Communication and Extension, Lady Irwin College, University of Delhi, India; ${ }^{2}$ Associate Professor, Department of Development Communication and Extension, Lady Irwin College, University of Delhi, India

\begin{tabular}{|c|c|c|c|c|c|c|c|c|}
\hline Abstract & Introduction & Methodology & $\underline{\text { Results }}$ & Conclusion & References & Citation & \multicolumn{2}{|c|}{ Tables / Figures } \\
\hline \multicolumn{9}{|c|}{ Corresponding Author } \\
\hline \multicolumn{8}{|c|}{$\begin{array}{l}\text { Miss Sabhya Juneja, M.Sc., Ph.D. Scholar, Department Development Communication and Extension, Lady } \\
\text { Irwin College, University of Delhi, Delhi, India. } \\
\text { E Mail ID: sabhyajuneja@gmail.com }\end{array}$} & 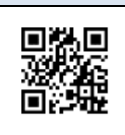 \\
\hline
\end{tabular}

\section{Citation}

Juneja S, Kumar A. Factors influencing Community Healthcare Worker's adoption of mobile health technology (mhealth): A case of sangini supportive supervision (sangini) app, Uttar Pradesh, India. Indian J Comm Health. 2021;33(3):519-522. https://doi.org/10.47203/IJCH.2021.v33i03.020

Source of Funding: Indian Council of Social Science Research (ICSSR), India Conflict of Interest: None declared

\section{Article Cycle}

Received: 19/05/2021; Revision: 13/08/2021; Accepted: 26/08/2021; Published: 30/09/2021

This work is licensed under a Creative Commons Attribution 4.0 International License.

\section{Abstract}

Background: Community Health Workers (CHWs) are agents in delivering primary healthcare. mhealth is being used to improve their performance. However, there are little evidences on factors influencing adoption of technology. Henceforth, sangini app was undertaken for analysis. Objective: To investigate factors of adoption of sangini app among users and nonusers. Methods \& statistical analysis: Constructs from Technology Acceptance Model (TAM) and Theory of Self-Efficacy (SE) were used as tools for study. The study used an experimental study design Kaushambi and Pratapgarh districts of Uttar Pradesh (U.P.), India was selected as intervention and control groups respectively. The study sample consisted of CHWs i.e. 90 Sangini and 270 ASHAs. Two sample $t$ test with equal variances and univariate regression analysis was applied. Results: TA and SE were predicators however; individual characters didn't impact adoption of mhealth. Conclusion: There is need to comprehend factors influencing adoption of mhealth to improve performance of CHWs.

\section{Keywords}

CHWs; TAM; Self-efficacy; mhealth; Sangini; ASHAs; Humans; Telemedicine

\section{Introduction}

Community Health Workers (CHWs) are key agents to achieve sustainable development goals (SDGs) by promoting and delivering healthcare services (1). In order to provide quality services, it is essential to maximize their productivity (2). Mobile health (mhealth) offers promising results to improve healthcare system in low- and middleincome countries (3). Despite of numerous initiatives there are little evidences on factors stimulating decision of CHWs to adopt mobile technology. Technology acceptance model (TAM) is the most promising model to explain user acceptability (4). The elementary model outlines a facilitating role of Perceived Usefulness (PU), Perceived ease of use (PEOU), Attitude (AT) and behaviour (BI) between external variables and system usage (5). Evidences also demonstrate use of new technology depends on individual's perceived self-efficacy (SE) (6) as individuals who feel efficacious chooses more challenging tasks and adopts technology faster (7).

\section{Aims \& Objectives}

To investigate factors of adoption of sangini app between users and non-users

\section{Material \& Methods}

Project context: The sangini app is an android and web based, multi-media healthcare application for sangini (appointed under NRHM, at block level at a ratio of 1:20 ASHAs) (8) who acts as supervisor of ASHA and are the crucial link between the community and the health system. Catholic Relief Services (CRS) piloted and supported mobile health application in Kaushambi district of Uttar Pradesh which is now run by NRHM, U.P. The sangini app aims to improve performance of sangini 
through improved knowledge and skills on supportive supervision (9).

Study Population, Area and Sampling Procedure: An experimental study design was used. The study was based in Uttar Pradesh, U.P. and was conducted from February to December 2019. For the study, intervention group was purposely selected where the sangini app intervention was implemented to its fullest and earliest since 2014 in the Kaushambi district of U.P. Furthermore, the control group was selected by matching for IMR and MMR +3 statistics of Kaushambi henceforth Pratapgarh district was selected. Multi-stage random sampling technique was used.

The sample included key CHWs i.e. Sanginis (Primary users of the app) and ASHAs. All sangini working in intervention group i.e. 67 sangini were selected for the study. For selection of ASHAs for the intervention group sample size was computed on $0.4 /$ SD with $95 \%$ confidence level and 90\% power, with 201 ASHAs per group considering nonresponse rate. From the list of 20 ASHAs under each sangini hence 3 ASHAs were randomly selected. Due to time constraints only $50 \%$ of sample was taken from control group. Out of the total sample incomplete and missing data was excluded thus a total of 90 sangini and 270 ASHAs formed the sample for the study. Consent was taken from all respondents before interview.

Tools and techniques: In order to analyze factors of adoption TAM was used as a framework which includes PU, PEOU, AT, BI. We also included statements of perceived Self-efficacy (SE) and collected information on Individual Characteristics (IC) (age, education level and work experience) as additional constructs. For this study a composite score was formed for TAM variables (PU, PEOU, AT, BI) and is titled as technology acceptance (TA). The study included five-points Likert scale from "strongly disagree" to "strongly agree".

The statements were translated to their local language i.e., Hindi Language. After completing pilot study, irrelevant questions were removed, validity and reliability assessment was completed. The Cronbach's alpha was tested it was found that all values were within acceptable range. The data was collected by visiting site and by meeting respondents in their familiar setting i.e., at the health center. The questionnaire was orally narrated and filled by the researcher. Respondent's confidentiality was maintained by not collecting any personal identifiable information.

Ethical Approval: Ethical approval was obtained from Institutional Ethics Committee, Lady Irwin College, University of Delhi.

The following hypothesis were formulated on the basis of literature review:

- HI: There is no significant difference between perceived self-efficacy level of $\mathrm{CHWs}$ where sangini app is implemented and where it is not implemented
[Factors influencing...] | Juneja $S$ et al

- HII: There is no significant difference between technology acceptance level of CHWs where sangini app is implemented and where it is not implemented

- HIII: Perceived self-efficacy level of CHWs would have no effect on technology acceptance level

- HIV: Individual characteristics of CHWs will have no effect on technology acceptance level

Data analysis: The difference between mean of two groups were analyzed using two sample t test with equal variances. The relationship and association between dependent and independent variables were tested using regression with the statistical software Stata 14, the statistical analysis was performed and results were calculated. To consider the effect of clustering (ASHA under Sangini) generalized estimating equation was used to see the difference in two group.

\section{Results}

$\mathrm{HI}$ \& HII were tested with CHWs in both groups. Hypothesis were tested using two sample t test with equal variances using STATA.

Sangini

As given in (Table 1) we found average of SE of Sangini in intervention group is significantly higher than in control group [p value - 0.000]. It was also found average level of TA in intervention group is significantly higher than in control group [ $p$-value $=0.0000]$.

ASHA

As given in (Table 1) we found average of SE of ASHA in intervention group is significantly higher than in control group [ $p$ value - 0.000]. It was also found average level of TA in intervention group is significantly higher than in control group [p-value $=0.0000]$.

HIII \& HIV were tested with CHWs in both groups. The relationship and association of technology acceptance with individual characteristics and SE were tested using regression with the statistical software Stata, the statistical analysis was performed and results were calculated.

Sangini

As given in (Table 1 ) in univariate regression analysis we found SE was positively associated with TA $[\beta(95 \% \mathrm{Cl}): 1.10$ $(.83,1.38)]$. After adjusting age and using multivariable regression analysis we found $\mathrm{SE}$ was a significant independent predictor of TA. $[\beta(95 \% \mathrm{Cl}): 1.16,(.83,1.48)]$. ASHA

As given in (Table 1) in univariate regression analysis we found SE was positively corelated with TA [ $\beta(95 \% \mathrm{Cl}): 1.49$ $(1.41,1.57)]$. After adjusting age and using multivariable regression analysis we found $\mathrm{SE}$ was a significant independent predictor of TA. [ $\beta(95 \% \mathrm{Cl}): 1.49(1.41,1.58)]$

\section{Discussion}

M-Health interventions have the potential to streamline CHWs functioning, enhance their abilities and performance and improve community health outcomes. 
Our research tries to close the gap of insufficient evidences required to deliver an effective mhealth strategy by examining factors influencing adoption of technology by CHWs. Our study included 90 sangini and 270 ASHAs from intervention and control group. Of these most of the women are middle aged married women who are intermediate pass (Table 2 ) and have received training. There were only few variations in their years of work experience. In addition, $100 \%$ sangini had received additional training for operating sangini app in intervention group.

The study provided empirical evidences for the hypothesis tested. The results indicated significant positive difference between SE and TA amongst sangini in intervention and control groups. This may imply usage of mobile technology by sangini might increase their SE and TA. Correspondingly use of mobile technology by sangini who are the prime users of technology has also positively impacted the SE and TA of ASHAs under her supervision. Thus, this may imply usage of mobile technology can strengthen healthcare systems at all levels of $\mathrm{CHWs}$.

The regression analysis aids in concluding SE as the most important factor in acceptance towards technology thus confirming similar results of previous studies $(6,10)$. In contrast, IC such as age, education level and work experience does not impact the decision to adopt technology among CHWs. This may imply use mobile technology by CHWs might increase their perceived selfefficacy which might result in increased technology acceptance.

\section{Conclusion}

CHW's technology acceptance (PU, PEOU, AT, BI) and selfefficacy are the factors influencing adoption of mobile technology based sangini app. However, individual characters such as age, education level and work experience did not impact their adoption of mobile technology. There was no disparity between factors of adoption between users and non-users of sangini app. Despite variations in infrastructure and internet connectivity mobile technology is emerging as a solution in healthcare our study provides evidences to improve effectiveness of such initiatives. Thus, future mhealth app developers and program implementors can target specific needs of CHWs and its impact on overall healthcare system which will strengthen healthcare delivery and improve health outcomes.

\section{Recommendation}

There is a need to understand factors of adoption of mhealth by CHWs which would aid in maximising their productivity and thus strengthening healthcare delivery and improve health outcomes

\section{Limitation of the study}

Sample size was reduced to $50 \%$ in control group due to time constraints

\section{Relevance of the study}

The study provides evidences of focusing on factors such as technology acceptance and self-efficacy of CHW's which would lead to adoption of technology.

\section{Authors Contribution}

SJ: literature search, data acquisition, guarantor. SJ \& AK: conceptualization, design, definition of intellectual content, data analysis, statistical analysis, manuscript preparation, editing and review.

\section{Acknowledgement}

We greatly acknowledge the support received from the study participants, National Rural Health Mission (NRHM) Uttar Pradesh (U.P.), Government of India (GOI) and Catholic Relief Services (CRS) for giving permission to work with ASHA programme. We would also like to acknowledge Dr R.M. Pandey, Head of the department, Department of Bio-statistics, AlIMS, New Delhi for statistical guidance.

\section{References}

1. Maher D, Cometto G. Research on community-based health workers is needed to achieve the sustainable development goals. [Editorial] Bull World Health Organ 2016; 94: 786. Available

from: https://www.who.int/bulletin/volumes/94/11/16-185918/en/

2. Jaskiewicz W, Tulenko K. Increasing community health worker productivity and effectiveness: a review of the influence of the work environment. Human resources for health. 2012;10(1):19. Available from: https://human-resourceshealth.biomedcentral.com/articles/10.1186/1478-4491-10-38

3. Kahn JG, Yang JS, Kahn JS. 'Mobile'health needs and opportunities in developing countries. Health affairs. 2010;29(2):252-8. Available from: https://doi.org/10.1377/hlthaff.2009.0965

4. Hu PJ, Chau PY, Sheng OR, Tam KY. Examining the technology acceptance model using physician acceptance of telemedicine technology. Journal of management information systems. 1999;16(2):91-112. Available from: https://www.tandfonline.com/doi/abs/10.1080/07421222.19 99.11518247

5. Davis FD, Bagozzi RP, Warshaw PR. User acceptance of computer technology: A comparison of two theoretical models. Management science. 1989;35(8):982-1003. Available from: https://pubsonline.informs.org/doi/abs/10.1287/mnsc.35.8.9 $\underline{82}$

6. Compeau DR, Higgins CA. Computer self-efficacy: Development of a measure and initial test. MIS quarterly. 1995:189-211. Available from https://www.jstor.org/stable/pdf/249688.pdf?casa token=0L -I6UHYTkoAAAAA:B92aE9CXu2RShUcLnGDgJ-jwAQaYmB04OiJ5mCkfOILmIQyHAMgd20p3BbTn6TzdPOFX4rIVnmYnNgjIK9Y QBv0KVuwAxiM8AA2s0RpOSrICWTLYG86KA

7. Gandoy-Crego M, Clemente M, Gómez-Cantorna C, GonzálezRodríguez R, Reig-Botella A. Self-efficacy and health: the SEH scale. American journal of health behavior. 2016;40(3):389-95. Available from: https://doi.org/10.5993/AJHB.40.3.11

8. NRHM, n.d., Handbook of ASHA Facilitators. Available from: http://nhm.gov.in/images/pdf/communitisation/asha/Handb ook for ASHA Facilitators.pdf

9. Catholic Relief Services (CRS). ReMiND Project M-HEALTH SOLUTIONS TO SUPPORT ASHA SANGINIS FOR MATERNAL \& 
INDIAN JOURNAL OF COMMUNITY HEALTH / VOL 33 / ISSUE NO 03 / JUL-SEP 2021 CHILD SURVIVAL. [internet]. 2017 [cited 06 may 2017]. Available https://www crs.org/sites/default/files/toolsresearch/asha sa ngini crs 2pager 6may17.pdf

10. Zhang X, Han X, Dang Y, Meng F, Guo X, Lin J. User acceptance of mobile health services from users' perspectives: The role of
[Factors influencing...] | Juneja $S$ et al self-efficacy and response-efficacy in technology acceptance. Informatics for Health and Social Care. 2017;42(2):194-206. Available

from https://www.tandfonline.com/doi/abs/10.1080/17538157.20 $\underline{16.1200053}$

\section{Tables}

TABLE 1 TWO SAMPLE T TEST WITH EQUAL VARIANCES OF TA AND SE OF CHWS \& UNIVARIATE REGRESSION ANALYSIS OF SE AND IC WITH TA

\begin{tabular}{|c|c|c|c|c|}
\hline \multicolumn{5}{|c|}{ Two sample $t$ test with equal variances of TA and SE of CHWs } \\
\hline SANGINI & $\begin{array}{c}\text { Group (a) } \\
\text { mean } \pm S D \\
n=60\end{array}$ & $\begin{array}{l}\text { Group (b) } \\
\text { mean } \pm S D \\
n=30\end{array}$ & $\begin{array}{c}\text { Unadjusted } \\
\text { Difference }(95 \% \mathrm{Cl}) \\
\text { [p-value] }\end{array}$ & $\begin{array}{c}\text { Adjusted } \\
\text { Difference }(95 \% \mathrm{Cl}) \\
\text { [p-value] }\end{array}$ \\
\hline Self-efficacy (SE) & $\begin{array}{c}44 \\
\pm 2.7\end{array}$ & $\begin{array}{l}34.6 \\
\pm 3.3\end{array}$ & $\begin{array}{l}-9.32(-10.57 \\
-8.07)[0.000]\end{array}$ & $-9.13(-10.70,-7.57)[0.000]$ \\
\hline $\begin{array}{c}\text { Technology } \\
\text { Acceptance (TA) }\end{array}$ & $\begin{array}{r}91.21 \\
+5.08\end{array}$ & $\begin{array}{r}80.69 \\
+11.60\end{array}$ & $\begin{array}{l}-10.51(-13.84 \\
-7.18)[0.000]\end{array}$ & $-11.13(-15.33,-6.93)[0.000]$ \\
\hline ASHA & $\begin{array}{l}\text { Group (a) } \\
\text { mean } \pm S D \\
n=180\end{array}$ & $\begin{array}{c}\text { Group (b) } \\
\text { mean } \pm S D \\
n=90\end{array}$ & $\begin{array}{c}\text { Unadjusted } \\
\text { Diffrence }(95 \% \mathrm{Cl}) \\
\text { [p-value] }\end{array}$ & $\begin{array}{c}\text { Adjusted } \\
\text { Diffrence }(95 \% \mathrm{Cl}) \\
\text { [p-value] }\end{array}$ \\
\hline Self-efficacy (SE) & $43.78 \pm 2.34$ & $\begin{array}{l}17.77 \\
\pm 6.29\end{array}$ & $-26.09(-27.52-24.67)[0.000]$ & $-26.04(-27.49,-24.59)[0.000]$ \\
\hline $\begin{array}{c}\text { Technology } \\
\text { Acceptance (TA) }\end{array}$ & $93.5 \pm 2.26$ & $\begin{array}{r}50.91 \\
+11.65 \\
\end{array}$ & $-43.57(-46.49,-40.65)[0.000]$ & $\begin{array}{c}-43.64(-46.56,-40.72) \\
{[0.000]}\end{array}$ \\
\hline \multicolumn{5}{|c|}{ Univariate regression analysis of SE and IC with TA } \\
\hline SANGINI & \multicolumn{2}{|c|}{$\begin{array}{c}\text { Unadjusted Difference }(95 \% \mathrm{Cl})[\mathrm{p}- \\
\text { value] }\end{array}$} & \multicolumn{2}{|c|}{$\begin{array}{l}\text { Adjusted Difference } \\
(95 \% \mathrm{Cl})[\mathrm{p} \text {-value] }\end{array}$} \\
\hline Self-efficacy (SE) & \multicolumn{2}{|c|}{$1.10,(.83,1.38)[0.000]$} & \multicolumn{2}{|c|}{ (95\%Cl) [p-value] } \\
\hline Age & \multicolumn{2}{|c|}{$-.275(-.61, .05)[0.106]$} & \multicolumn{2}{|c|}{$.041(-.23, .31)[0.770]$} \\
\hline Education Level & \multicolumn{2}{|c|}{$-1.39(-2.54,-.24) 0.018]$} & \multicolumn{2}{|c|}{$.29(-.73,1.33)[0.567]$} \\
\hline ASHA & \multicolumn{2}{|c|}{$\begin{array}{c}\text { Unadjusted Difference }(95 \% \mathrm{Cl})[\mathrm{p}- \\
\text { value] }\end{array}$} & \multicolumn{2}{|c|}{$\begin{array}{l}\text { Adjusted Difference } \\
(95 \% \mathrm{CI})[\mathrm{p} \text {-value] }\end{array}$} \\
\hline Self-efficacy (SE) & \multicolumn{2}{|c|}{$1.49(1.41,1.57)[0.000]$} & \multicolumn{2}{|c|}{$1.49(1.41,1.58)[0.000]$} \\
\hline Age & \multicolumn{2}{|c|}{$-.78(-1.10,-.47)[0.000]$} & \multicolumn{2}{|c|}{$.02(-.12, .17)[0.751]$} \\
\hline Education Level & \multicolumn{2}{|c|}{$-1.05(-2.32, .22)[0.105]$} & \multicolumn{2}{|c|}{$-.14(-.69, .41)[0.611]$} \\
\hline
\end{tabular}

\section{TABLE 2 INDIVIDUAL CHARACTERS OF CHWS}

\begin{tabular}{|c|c|c|c|}
\hline \multirow[t]{3}{*}{ SANGINI } & Group (a) & Group (b) & \multirow[t]{3}{*}{ P value } \\
\hline & mean $\pm S D$ & Mean \pm SD & \\
\hline & $n=60$ & $n=\mathbf{3 0}$ & \\
\hline Age & $36.1 \pm 4.8$ & $41 \pm 5.8$ & 0.0001 \\
\hline Education Level & $12.5 \pm 1.0$ & $14.0 \pm 2$ & $<0.0001$ \\
\hline \multirow[t]{3}{*}{ ASHA } & Group (a) & Group (b) & \multirow[t]{3}{*}{$P$ value } \\
\hline & mean $\pm S D$ & Mean \pm SD & \\
\hline & $n=180$ & $n=90$ & \\
\hline Age & $35.5 \pm 7.58$ & $40.4 \pm 6.25$ & 0.0001 \\
\hline Education Level & $10.67 \pm 2.07$ & $11.03 \pm 1.67$ & 0.1201 \\
\hline
\end{tabular}

